УДК 550.812.1; 553.632; 553.98

\title{
ИСПОЛЬЗОВАНИЕ ВЕРОЯТНОСТНЫХ МОДЕЛЕЙ НЕФТЕГАЗОНОСНОСТИ В ЦЕЛЯХ РАНЖИРОВАНИЯ ПЕРСПЕКТИВНЫХ СТРУКТУР, НАХОДЯЩИХСЯ В ПРЕДЕЛАХ ВЕРХНЕКАМСКОГО МЕСТОРОЖДЕНИЯ КАЛИЙНО-МАГНИЕВЫХ СОЛЕЙ
}

\author{
Галкин Владислав Игнатьевич1, \\ vgalkin@pstu.ru
}

\author{
Мелкишев Олег Александрович 1 , \\ melkishev@pstu.ru
}

\author{
Варушкин Станислав Владимирович2,1, \\ geologist-07@mail.ru \\ 1 Пермский национальный исследовательский политехнический университет, \\ Россия, 614990, г. Пермь, Комсомольский пр., 29. \\ 2 ООО «ЛУКОЙЛ-ПЕРМЬ», \\ Россия, 614990, г. Пермь, ул. Ленина, 62.
}

\begin{abstract}
Актуальность работы. За последние годы в Пермском крае произошли существенные изменения территориального распределения запасов и ресурсов углеводородов. В настоящее время на территории платформенной части Пермского края открыты и разведаны все крупные и средние месторождения нефрти и газа, тогда как в пределах Соликамского нефтегазоносного района Волго-Уральской нефтегазоносной провинции возможность открытия таких месторождений реально существует, особенно на территории Верхнекамского месторождения калийно-магниевых солей. Выбор объектов и определение очередности их ввода в поисково-оценочное бурение играют важное значение для успешности проведения геологоразведочных работ.

Цель: определить первоочередные объекты для постановки поисково-оценочного бурения на основе статистических моделей прогноза нефтегазоносности.

Объекты: выявленные и подготовленные нефртегазоперспективные структуры Соликамского нефттегазоносного района Волго-Уральской нефртегазоносной провинции, находящиеся в контуре Верхнекамского месторождения калийно-магниевых солей. Методы: построение многомерных моделей методом пошагового регрессионного анализа.

Результаты. Для комплексного проведения ранжирования всех имеющихся структур, находящихся на территории Верхнекамского месторождения калийно-магниевых солей, был рассчитан комплексный зонально-локальный критерий нефртегазоносности - Рнкомп. Проведена оценка влияния морфологических (Руквморф), миграционных (Ркм), геохимических (Руквгх) параметров и критерия по данным газопроявлений (Рнмnх) на комплексный показатель Рнкомп. Из анализа построенных моделей следует, что критерии Руквморф, Руквгх являются более универсальными, тогда как Ркм, Рнмпх проявляются только для выборок, которые включают структуры с наибольшими значениями комплексного показателя Рнкомп. Установлены наиболее перспективные структуры с точки зрения первоочередности ввода в поисково-оценочное бурение.
\end{abstract}

\section{Ключевые слова: \\ Верхнекамское месторождение калийно-магниевых солей, Соликамский нефртегазоносный район, Волго-Уральская нефртегазоносная провинция, пошаговый регрессионный анализ, условная комплексная вероятность, поисково-оценочное бурение, геолого-разведочные работы.}

Оценка нефтеносности территории Верхнекамского месторождения калийно-магниевых солей (ВКМКС) является достаточно сложной, так как в верхней части разреза располагается уникальное месторождение, что затрудняет здесь проведение поискового бурения [1-5]. Поэтому для оценки нефтеносности предлагается использовать дополнительные критерии, связанные с наличием этой толщи. Дополнительно к морфологическим, геохимическим и миграционным критериям авторы данной статьи предлагают использовать газоносность самой соленосной толщи. Поэтому для оценки нефтегазоносности структур были использованы четыре группы показателей, разработанные специально для территории ВКМКС.

Геологический разрез рассматриваемой территории представлен отложениями вендского комплекса, девонской, каменноугольной, пермской систем и четвертичными отложениями (рис. 1).
Особенности и математический аппарат разработки геолого-математических моделей для решения геологических задач приведены в работах как отечественных, так и зарубежных авторов [6-26].

Первая группа оценивает нефтеносность по морфологическим показателям. В работах [27, 28] установлено, что помимо зональных характеристик, на оценку нефтегазоносности в значительной степени влияют морфологические характеристики локальных структур. Рассматривались значения амплитуд (А), площадей $(\mathrm{S})$ и интенсивности $(\mathrm{A} / \sqrt{ } \mathrm{S})$ по основным отражающим горизонтам структур. В результате по показателям данной группы был разработан комплексный критерий - Рукв многомерного вероятностного критерия Рукв нефтяных структур равен 0,708 д. ед., для пустых 0,188 д. ед. Статистические характеристики критерия являются информативными: $\mathrm{t}$-критерий Стьюдента составляет 6,98 при $\mathrm{p}=0,000$. 


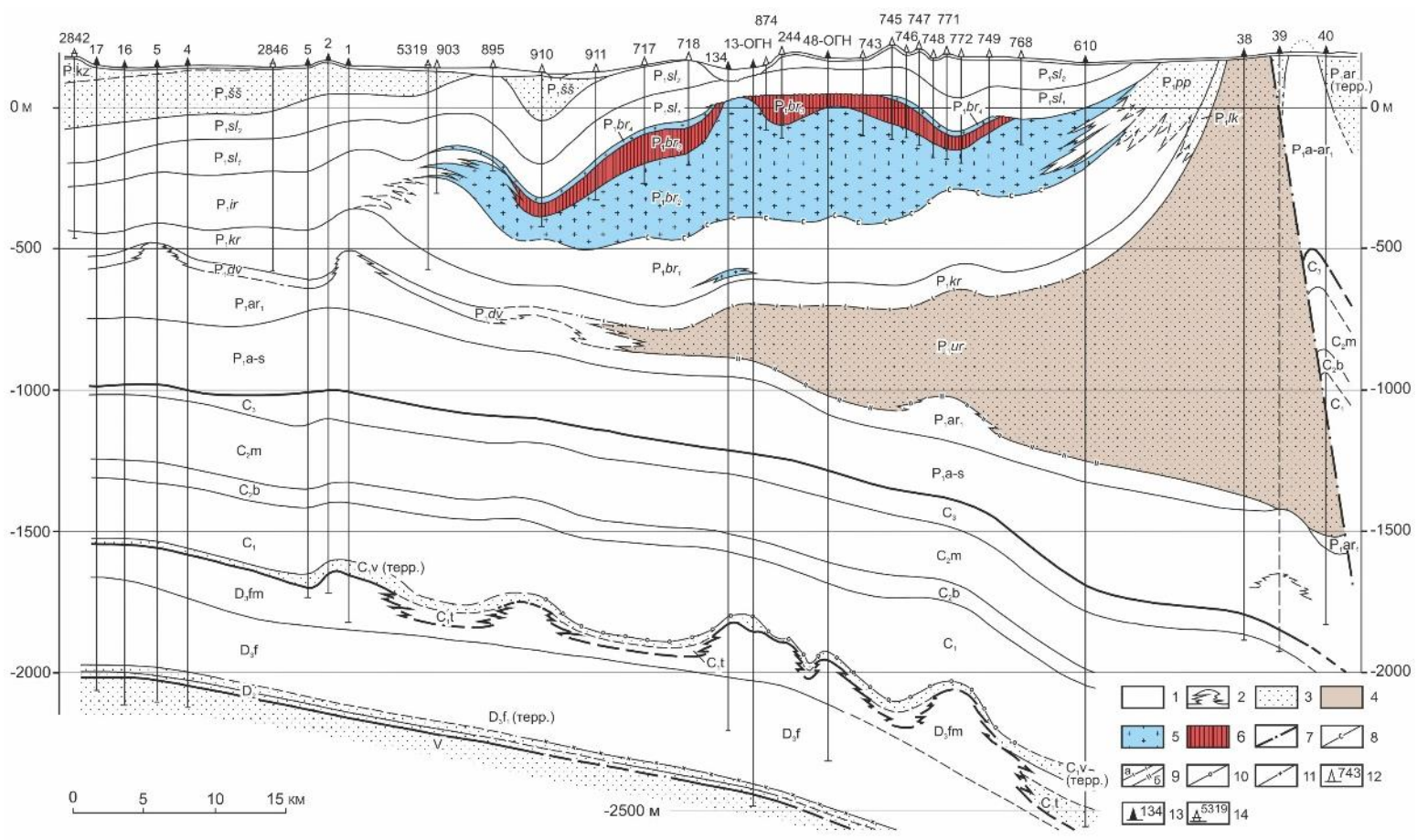

Pис. 1. Схематичный геологический разрез Соликамской впадины [1]

Fig. 1. Schematic geological section of the Solikamsk depression [1]

По геохимическим показателям разработаны критерии - Рукв гх и Ркм [29, 30]. Для построения геохимических моделей использованы показатели содержания рассеянного органического вещества (РОВ), содержания органического углерода в РОВ $\left(\mathrm{C}_{\text {орг }}\right)$, концентраций петролейных, хлороформенных и спиртобензольных битумоидов $\left(5_{\text {пэ, }} Б_{\text {хл }}, 5_{\text {сб }}\right.$ и $\left.Б_{\text {хл }} / Б_{\text {сб }}\right)$ и битумоидный коэффициент ( $\beta$ ) по основным нефтематеринским толщам в разрезе Соликамской депрессии. Среднее значение критерия Рукв гх для нефтяных структур равно 0,614 д. ед., для пустых - 0,283 д. ед. Статистические характеристики критерия являются информативными: $\mathrm{t}$-критерий Стьюдента составляет 4,20 при p $=0,000$.

Миграционный критерий Ркм $[29,30]$ основан на разделении классов по трем характеристикам: минимальное расстояние от центров с повышенными значениями Рукв гх до центра локальных структур $\left(\mathrm{L}_{\text {гео }}\right)$, расстояния от структур до ближайших разломов $\left(\mathrm{L}_{\text {разл }}\right)$ и показателя дальности субвертикальной миграции углеводородов $\left(\mathrm{L}_{\text {мигр }}\right)$. Среднее значение критерия Ркм для нефтяных структур равно 0,592 д. ед., для пустых - 0,452 д. ед. Статистические характеристики критерия являются информативными: t-критерий Стьюдента составляет 3,73 при р $=0,000$.

По геохимическим показателям разработан критерий Рукв гх $[29,30]$. Дополнительно к этим критериям разработан показатель, который оценивает процессы субвертикальной миграции углеводородов из нижерасположенных залежей нефти и газа, которые были зарегистрированы в виде газопроявлений в соленосной толще ВКМКС - $\mathrm{PH}_{\mathrm{MNX}}$ [31]. В качестве источников информации выступали данные о газопроявлениях, зафиксированных при бурении солеразведочных скважин в соленосной толще ВКМКС, которые при- ведены в архивных данных и отчетах о поисковооценочных работах. Эти данные были обобщены и использованы для построения вероятностностатистической модели прогноза нефтегазоносности. В состав зонального комплексного критерия вошли группы вероятностей мощности пластов $(\mathrm{PH}(\mathrm{Zm})$, $\left.\operatorname{RES}_{\mathrm{PH}_{\mathrm{Z}}(\mathrm{Zm}) \text { лин }}\right)$, абсолютных отметок $(\mathrm{Pн}(\mathrm{ZH}))$ и химического состава солей $(\mathrm{PH}(\mathrm{Zx}))$. Среднее значение критерия $\mathrm{PH}_{\mathrm{MNX}}$ для нефтяных структур равно 0,526 д. ед., для пустых - 0,422 д. ед. Статистические характеристики критерия являются информативными: Стьюдента составляет 5,40 при $p=0,000$. По значениям $\mathrm{P}_{\text {MNX }}$, при использовании данных по всем изучаемым скважинам, построена схема изменения распределения $\mathrm{PH}_{\mathrm{MNX}}$ по площади исследований (рис. 2).

Вне площади разрабатываемых месторождений наибольшими значениями комплексного критерия

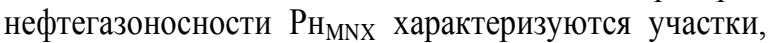
расположенные севернее от месторождения им. Сухарева и западнее от Логовского месторождения. Максимальные значения $\mathrm{P}_{\mathrm{MNX}}$ в этих районах равны 0,75 д. ед. (скв. № 623) и 0,69 д. ед. (скв. № 662) соответственно. На остальной территории выделяется ряд локальных аномалий, где $\mathrm{PH}_{\mathrm{MNX}}>0,60$ д. ед.: в южной части - к северу и западу от месторождения им. Архангельского, в центральной части - в непосредственной близости к Новологовской, Клестовской, Стрелецкой структурам и в районе Боровицкого прогиба ВКМКС вне границ Березниковского палеоплато, в северной части - к югу от Озерного месторождения.

В табл. 1 представлены средневзвешенные по площади значения вероятностных характеристик Рукв турам в рамках изучаемого района. 


\section{Условные обозначения}

- $\quad$ Прогнозные скв.

- Вне контура нефттегазоносности

○ В контуре нестегазоносности

\section{Границы}

-----" Предуральского краевого прогиба

$====$ Крупных структур

— Березниковского палеоплато

Клестовская Перспективные структуры

Логовске Месторождения

Контур ВКМКС

Рн(MNX), д.ед.
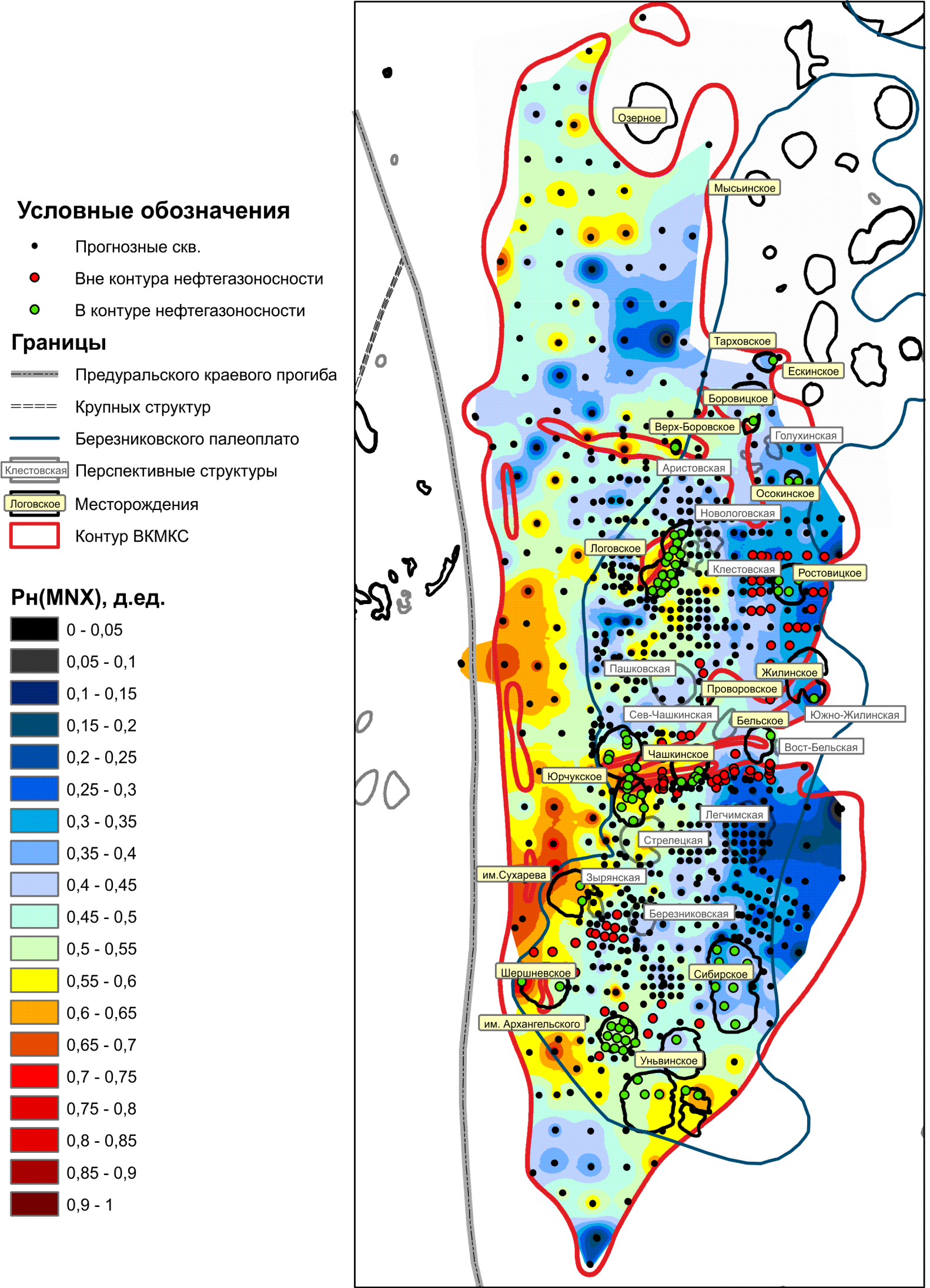

Pис. 2. Прогноз нефтегазоносности территории ВКМКС по критерию $P_{H_{M N X}}$ [31]

Fig. 2. Forecast of oil and gas content of the Verkhnekamsky deposit of potassium and magnesium salts (VFPMS) according to the $P n_{M N X}$ criterion [31] 
Таблица 1. Вероятностные характеристики перспективных структур ВКМКС

Table 1. Probabilistic characteristics of perspective structures of the VFPMS

\begin{tabular}{|c|c|c|c|c|}
\hline \multirow{2}{*}{$\begin{array}{l}\text { Название структуры } \\
\text { Structure name }\end{array}$} & $\begin{array}{l}\text { Рукв } \\
\text { Pukv } \\
\text { Puk morf }\end{array}$ & $\begin{array}{l}\text { Рукв }_{\text {rx }} \\
\text { Pukv }_{\text {gh }}\end{array}$ & $\begin{array}{l}\text { Pкм } \\
\text { Pkm }\end{array}$ & $\begin{array}{l}\mathrm{PH}_{\mathrm{MNX}} \\
\mathrm{Pn}_{\mathrm{MNX}}\end{array}$ \\
\hline & \multicolumn{4}{|c|}{ д. ед./unit fraction } \\
\hline $\begin{array}{l}\text { Аристовская } \\
\text { Aristovskaya }\end{array}$ & 0,11 & 0,35 & 0,67 & 0,42 \\
\hline $\begin{array}{l}\text { Голухинская } \\
\text { Golukhinskaya }\end{array}$ & 0,43 & 0,30 & 0,65 & 0,38 \\
\hline $\begin{array}{l}\text { Клестовская } \\
\text { Klestovskaya }\end{array}$ & 0,05 & 0,92 & 0,61 & 0,50 \\
\hline $\begin{array}{l}\text { Новологовская } \\
\text { Novologovskaya }\end{array}$ & 0,32 & 0,80 & 0,63 & 0,42 \\
\hline $\begin{array}{l}\text { Березниковская } \\
\text { Bereznikovskaya }\end{array}$ & 0,59 & 0,81 & 0,73 & 0,44 \\
\hline $\begin{array}{l}\text { Восточно-Бельская } \\
\text { Vostochno-Belskaya }\end{array}$ & 0,17 & 0,98 & 0,74 & 0,44 \\
\hline $\begin{array}{l}\text { Стрелецкая } \\
\text { Streletskaya }\end{array}$ & 0,68 & 0,75 & 0,73 & 0,58 \\
\hline $\begin{array}{l}\text { Северо-Чашкинская } \\
\text { Severo-Chashkinskaya }\end{array}$ & 0,51 & 0,93 & 0,68 & 0,45 \\
\hline $\begin{array}{l}\text { Пашковская } \\
\text { Pashkovskaya }\end{array}$ & 0,96 & 0,70 & 0,48 & 0,46 \\
\hline $\begin{array}{l}\text { Южно-Жилинская } \\
\text { Yuzhno-Zhilinskaya }\end{array}$ & 0,83 & 0,94 & 0,66 & 0,37 \\
\hline $\begin{array}{l}\text { Легчимская } \\
\text { Legchimskaya }\end{array}$ & 0,99 & 0,93 & 0,80 & 0,27 \\
\hline $\begin{array}{l}\text { Зыряновская } \\
\text { Zyryanovskaya }\end{array}$ & 0,99 & 0,89 & 0,73 & 0,57 \\
\hline
\end{tabular}

Применение методики вычисления условной комплексной вероятности по всем представленным группам показателей позволит более разносторонне выполнить оценку нефтеносности локальных структур. Для этого предлагается использовать следующую формулу расчета комплексного зонально-локального критерия нефтегазоносности:

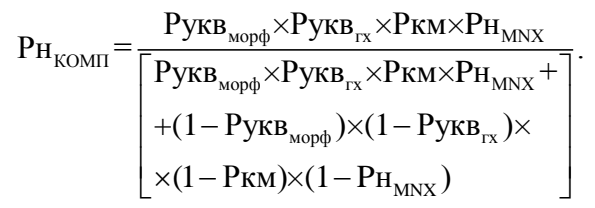

По предлагаемой формуле рассчитаны значения критерия Рнкомп для всех выявленных и подготовленных структур, расположенных в контуре ВКМКС, которые составляют (д. ед.):

1. Аристовская - 0,0891 ;

2. Голухинская $-0,2690$;

3. Клестовская - 0,4863 ;

4. Новологовская - 0,6989;

5. Березниковская - 0,9287;

6. Восточно-Бельская - 0,9573;

7. Стрелецкая - 0,9597;

8. Северо-Чашкинская - 0,960 ;

9. Пашковская - 0,9778;

10. Южно-Жилинская - 0,9887;

11. Легчимская $-0,9995$;

12. Зыряновская $-0,9997$.

Для оценки вклада в значения Рнномп различных сочетаний вероятностных критериев Рукв

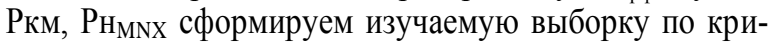
терию Рнкомп от максимального (Рнкомп $=0,9997$ д. ед.) до минимального (Рнкомп $=0,0891$ д. ед.) значений.

Оценку влияния критериев Рукв

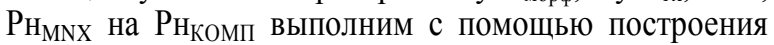
многомерных моделей, при этом строить их будем с помощью пошагового регрессионного анализа. Первая модель будет построена по трем структурам с максимальными значениями Рнкомп (табл. 1). Следующая модель будет построена при $\mathrm{n}=4$ и так далее до $\mathrm{n}=12$. Таким образом, были построены 10 уравнений регрессии, вид которых приведен в табл. 2.

Таблица 2. Многомерные уравнения регрессии для анализа формирования значений Рн Комп

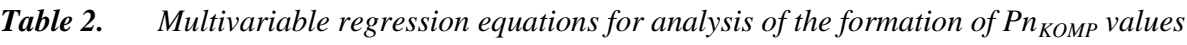

\begin{tabular}{|c|c|c|c|c|c|c|c|}
\hline \multirow{2}{*}{$\begin{array}{c}\text { Интервал построения моделей } \\
\text { по Рнкомп, Д. ед. } \\
\text { Interval of model building } \\
\text { according to } \mathrm{Pn}_{\mathrm{KOMP}} \text {, unit fraction }\end{array}$} & \multirow{2}{*}{$\begin{array}{c}\text { Номера структур, по кото- } \\
\text { рым построены модели } \\
\text { Numbers of structures } \\
\text { included in the model } \\
\end{array}$} & \multirow{2}{*}{$\begin{array}{c}\text { Свободный } \\
\text { член } \\
\text { Intercept term }\end{array}$} & \multicolumn{4}{|c|}{ Угловой коэффициент/Slope term } & \multirow[b]{2}{*}{$\mathrm{R}$} \\
\hline & & & $\begin{array}{l}\text { Рукв }_{\text {морф }} \\
\text { Pukv }_{\text {morf }}\end{array}$ & $\begin{array}{l}\text { Pукв }_{\text {гx }} \\
\text { Pukv }_{\text {gh }}\end{array}$ & $\begin{array}{l}\text { Ркм } \\
\text { Pkm }\end{array}$ & $\begin{array}{l}\mathrm{PH}_{\mathrm{MNX}} \\
\mathrm{Pn}_{\mathrm{MNX}}\end{array}$ & \\
\hline $0,989-0,999$ & $10-12$ & 0,937 & 0,067 & $-0,004$ & - & 0,019 & 0,999 \\
\hline $0,978-0,999$ & $9-12$ & 0,921 & 0,011 & - & 0,078 & 0,019 & 0,999 \\
\hline $0,960-0,999$ & $8-12$ & 0,818 & 0,089 & 0,104 & $-0,008$ & 0,013 & 0,999 \\
\hline $0,959-0,999$ & $7-12$ & 0,822 & 0,087 & 0,095 & - & 0,013 & 0,999 \\
\hline $0,957-0,999$ & $6-12$ & 0,845 & 0,065 & 0,097 & - & - & 0,967 \\
\hline $0,929-0,999$ & $5-12$ & 0,800 & 0,077 & 0,135 & - & - & 0,875 \\
\hline $0,699-0,999$ & $4-12$ & 0,454 & 0,209 & 0,403 & - & - & 0,710 \\
\hline $0,486-0,999$ & $3-12$ & 0,317 & 0,715 & - & 0,538 & - & 0,790 \\
\hline $0,269-0,999$ & $2-12$ & $-0,111$ & 0,437 & 0,849 & - & - & 0,886 \\
\hline $0,089-0,999$ & $1-12$ & $-0,216$ & 0,471 & 0,945 & - & - & 0,935 \\
\hline
\end{tabular}

Анализ построенных моделей показывает, что критерий Рукв 10 моделей, критерии Рукв ${ }_{\text {гx }}$, РН $_{\mathrm{MNX}}$, Ркм соответственно при построении 8, 4 и 3 моделей. Это свидетельствует о том, что критерии Рукв морф , Рукв более универсальными, тогда как Ркм, $\mathrm{PH}_{\mathrm{MNX}}$ характеризуют особенность их проявления только для тех

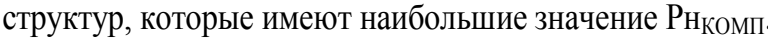
Вероятно, проявление этих особенностей может более надежно оценить нефтеносность этих структур.
Наблюдается обратная линейная зависимость между значениями РНкомп и Рукв морф$_{\text {, Рукв }}$ г. Данный факт объясняется тем, что при увеличении значений по критерию Рнкомп в выборку входят высокоамплитудные структуры, при этом значения Рукв меньший вклад. По причине расположения наиболее перспективных структур выборки 5-12 в центральной геохимической аномалии наблюдается снижение значений по геохимическому критерию Рукв 


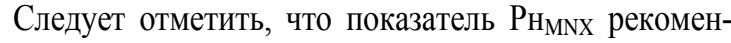
дуется использовать при построении моделей, которые характеризуются максимальными значениями по комплексному критерию. Вклад в регрессию для $\mathrm{PH}_{\mathrm{MNX}}$ положителен, таким образом, чем больше значение комплексного критерия по данным газопроявлений, тем выше общая вероятность нефтегазоносности.

Изменение значений коэффициента корреляции $\mathrm{R}$ от Рнкомп приведено на рис. 3 .

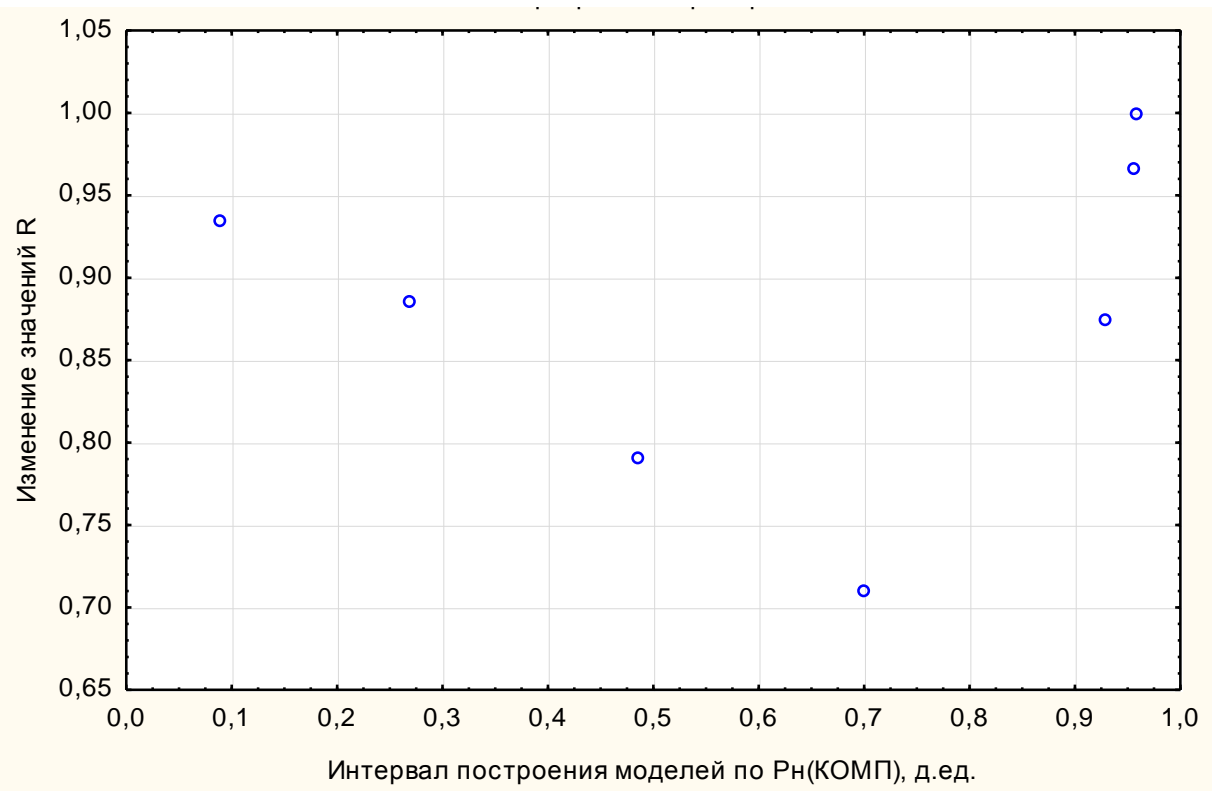

Pис. 3. Изменение коэффициента $R$ от $P{ }_{\text {комп }}$

Fig. 3. Change in the coefficient $R$ from $P n_{\text {KOMP }}$

Отсюда видно, что в пределах графика выделяются два вида соотношений между $\mathrm{R}$ и Рнкомп. При значениях $\mathrm{PH}_{\text {комп }}>0,7$ д. ед. наблюдается уменьшение значений $\mathrm{R}$ от 0,9997 до 0,709 д. ед., далее происходит повышение значений при уменьшении Рнкомп. Данное обстоятельство можно объяснить тем, что при $\mathrm{P}_{\text {комп }}>0,7$ д. ед. наблюдается формирование значений за счет всех разработанных критериев, тогда как при $\mathrm{PH}_{\text {комп }}<0,7$ д. ед. влияние Ркм, $\mathrm{PH}_{\mathrm{MNX}}$ не наблюдается. Поэтому для прогнозных оценок для выделения первоочередных объектов поисков УВ целесообразно использовать те модели, в которых присутствуют все разработанные критерии. Таким условиям удовлетворяет только одна модель, которая построена в диапазоне 0,999-0,960 д. ед.

\section{Заключение}

Предложенная методика прогноза нефтегазоносности позволяет на базе морфологических, геохимических, миграционных критериев и вероятностной модели нефтегазоносности по данным газопроявлений соленосной толщи отранжировать перспективные объекты по перспективности для последующей постановки детальных ГРР.

\section{СПИСОК ЛИТЕРАТУРЫ}

1. Кудряшов А.И. Верхнекамское месторождение солей. - Пермь Изд-во ГИ УрО РАН, 2013. - 429 с.

2. Варушкин С.В., Козлова И.А. Возможность проведения поисково-оценочных работ на объектах, расположенных под толщей калийно-магниевых солей Верхнекамского месторождения // Вестник Пермского национального исследовательского
Предложена формула расчета комплексного зонально-локального критерия нефтегазоносности Рнкомп. Проведена оценка вклада в значения комплексного критерия нефтегазоносности Рнкомп в разных сочетаниях вероятностных критериев Рукв

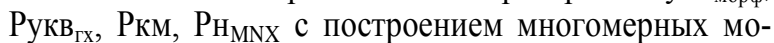
делей по 10 моделям. Из анализа построенных моделей следует, что критерии Рукв гх Рукв $_{\text {морф }}$ являются более универсальными, тогда как Ркм, $\mathrm{P}_{\mathrm{MNX}}$ проявляются только для выборок с наиболее перспективными структурами.

Благодаря расчету комплексного зональнолокального критерия нефтегазоносности РНкомп по группам показателей, разработанным специально для территории ВКМКС, и построения многомерных моделей установлено, что наиболее перспективными с точки зрения первоочередности постановки поисково-оценочного бурения являются Зыряновская, Легчимская, Южно-Жилинская, Пашковская и СевероЧашкинская структуры.

Применение результатов работы позволит снизить геологические риски при выборе объектов для проектирования ГРР и тем самым повысить успешность поисковых работ на рассматриваемом участке недр.

политехнического университета. Геология. Нефтегазовое и горное дело. - 2012. - Т. 11. - № 3. - С. 8-15.

3. Андрейко С.С., Иванов О.В., Литвиновская Н.А. Прогнозирование и предотвращение газодинамических явлений из почвы при проходке подготовительных выработок в подработанном массиве соляных пород. - Пермь: Изд-во Перм. нац. исслед. политехн. ун-та, 2015. - 158 с. 
4. Андрейко С.С., Иванов О.В., Нестеров Е.А. Борьба с газодинамическими явлениями при разработке Верхнекамского и Старобинского месторождений калийных солей // Научные исследования и инновации. - 2010. - Т. 3. - № 4. - С. 34-37.

5. Прогнозирование выбросоопасных зон пластов при разведке и разработке Верхнекамского месторождения калийных солей / С.С. Андрейко, О.В. Иванов, А.В. Харинцев, А.Н. Чистяков // Горный журнал. - 2008. - № 10. - С. 34-36.

6. Шайхутдинов А.Н. Разработка вероятностных моделей для прогноза нефтегазоносности верхнеюрских отложений (на примере территории деятельности ТПП «Когалымнефтегаз») // Вестник Пермского научно-исследовательского политехнического университета. Геология. Нефтегазовое и горное дело. - 2014. № 11. - C. 11-28.

7. Мартюшев Д.А., Зайцев Р.А. Влияние петрофизических параметров рифогенных карбонатных коллекторов нефтяных месторождений турнейско-фаменских отложений Верхнего Прикамья на продуктивность добывающих скважин // Известия Томского политехнического университета. Инжиниринг георесурсов. - 2019. - Т. 330. - № 11. - C. 77-85. DOI: $10.18799 / 24131830 / 2019 / 11 / 2350$

8. Кошкин К.А. Разработка вероятностно-статистических моделей для оценки перспектив нефтегазоносности пластов Тл2-б и Бб Пожвинского участка // Вестник Пермского научноисследовательского политехнического университета. Геология. Нефтегазовое и горное дело. - 2018. - Т. 17. - № 1. - С. 4-16. DOI: $10.15593 / 2224-9923 / 2018.1 .1$

9. Расторгуев М.Е. Использование дискриминантного анализа для интерпретации данных газового каротажа на примере Павловского нефтяного месторождения // Вестник Пермского научно-исследовательского политехнического университета. Геология. Нефтегазовое и горное дело. - 2019. - Т. 19. № 1. - C. 39-55. DOI: 10.15593/2224-9923/2019.1.4.

10. Фадеев А.П. Разработка методики оценки влияния закачки воды в пласт на добычу нефти на примере турнейских отложений Сосновского газонефтяного месторождения // Вестник Пермского научно-исследовательского политехнического университета. Геология. Нефтегазовое и горное дело. - 2018. T. 18. - № 2. - C. 157-177. DOI: 10.15593/2224-9923/2018.4.6.

11. Давыденко А.Ю. Вероятностно-статистические методы в геолого-геофизических приложениях. - Иркутск: Изд-во ИрГТУ, 2008. $-31 \mathrm{c}$

12. Дэвис Дж.С. Статистический анализ данных в геологии / пер. с англ. - М.: Недра, 1990. - Кн. 1. -319 с.

13. Михалевич И.М. Применение математических методов при анализе геологической информации (с использованием компьютерных технологий: Statistica). - Иркутск: Изд-во ИГУ, 2006. -115

14. Поротов Г.С. Математические методы моделирования в геологии. - СПб.: Изд-во Санкт-Петербургский государственный горный институт (технический университет), 2006. - 223 с

15. Чини Р.Ф. Статические методы в геологии / пер. с англ. - М. Изд-во «Мир», 1986. - 189 с.

16. Armstrong M. Basic linear geostatistics. - Berlin: Springer, 1998. $-155 \mathrm{p}$.

17. Bartels C.P.A., Ketellapper R.H. Exploratory and explanatory statistical analysis of spatial data. - Boston: Martinus Nijhoff Publishing, 1979. $-268 \mathrm{p}$.
18. Goodwin N. Bridging the gap between deterministic and probabilistic uncertainty quantification using advanced proxy based methods. SPE Reservoir Simulation Symposium. - Houston, Richardson Publ., 2015. - P. 1796-1868.

19. Darling T. Well logging and formation evaluation. - Eastbourne: Gardners Books, 2010. - $336 \mathrm{p}$

20. Tran D.T., Gabbouj M., Iosifidis A. Multilinear class-specific discriminant analysis // Pattern Recognition Letters. - 2017. V. 100. - P. 131-136. DOI: 10.1016/j.patrec.2017.10.027.

21. Horne R.N. Modern well test analysis: a computer aided approach. 2nd ed. - Palo Alto: PetrowayInc, 2006. -257 p.

22. Houze O., Viturat D., Fjaere O.S. Dynamic data analysis. - Paris: Kappa Engineering, 2008. - 694 p.

23. Maurya S.P., Singh N.P., Singh K.H. Geostatistical inversion. Seismic inversion methods: a practical approach. - Cham: Springer International Publ., 2020. - 216 p.

24. Montgomery D.C., Peck E.A. Introduction to liner regression analysis. - New York: John Wiley \& Sons, 1982. - 504 p.

25. Van Golf-Racht T.D. Fundamentals of fractured reservoir engineering. - Amsterdam, Oxford, New York: Elsevier scientific publishing company, 1982. $-709 \mathrm{p}$.

26. Yarus J.M. Stochastic modeling and geostatistics. - Tulsa, Oklahoma: AAPG, 1994. - $231 \mathrm{p}$.

27. К методике оценки перспектив нефтегазоносности Соликамской депрессии по характеристикам локальных структур / В.И. Галкин, И.А. Козлова, А.В. Растегаев, И.В. Ванцева, С.Н. Кривощеков, В.Л. Воеводкин // Нефтепромысловое дело. - 2010. - № 7. - С. 12-17.

28. Галкин В.И., Растегаев А.В., Галкин С.В. Вероятностностатистическая оценка нефтегазоносности локальных структур. - Екатеринбург: Изд-во УрО РАН, 2001. - 277 с.

29. О масштабах миграции углеводородов в пределах Соликамской депрессии Предуральского прогиба и возможностях ее использования для прогноза нефтегазоносности. К методике оценки перспектив нефтегазоносности Соликамской депрессии по характеристикам локальных структур / В.Л. Воеводкин, В.И. Галкин, И.А. Козлова, С.Н. Кривощеков, А.С. Козлов // Геология, геофизика и разработка нефтяных и газовых месторождений. - 2010. - № 12. - С. 6-12.

30. Галкин В.И., Кривощеков С.Н. Разработка вероятностностатистических моделей нефтегазоносности в условиях экологически напряженной территории Верхнекамского месторождения калийно-магниевых солей // Защита окружающей среды в нефтегазовом комплексе. - 2010. - № 11. - С. 52-53.

31. Разработка статистической модели прогноза нефтегазоносности по газовыделениям в толще Верхнекамского метосторождения калийно-магниевых солей / В.И. Галкин, О.А. Мелкишев, С.В. Варушкин, С.С. Андрейко, Т.А. Лялина // Вестник Пермского национального исследовательского политехнического университета. Геология. Нефтегазовое и горное дело. 2020. - T. 20. - № 1. - C. 4-13. DOI: $10.15593 / 2224-$ $9923 / 2020.1 .1$

Поступила 13.06.2020 г.

\section{Информация об авторах}

Галкин В.И., доктор геолого-минералогических наук, профессор, заведующий кафедрой геологии нефти и газа Пермского национального исследовательского политехнического университета.

Мелкишев О.A., кандидат технических наук, профессор, доцент кафедры геологии нефти и газа Пермского национального исследовательского политехнического университета.

Варушкин C.B., ведущий геолог ООО «ЛУКОЙЛ-ПЕРМЬ»; аспирант кафедры геологии нефти и газа Пермского национального исследовательского политехнического университета. 
UDC 550.812.1; 553.632; 553.98

\title{
USE OF PROBABILISTIC MODELS OF OIL AND GAS POTENTIAL FOR RANKING THE PERSPECTIVE STRUCTURES LOCATED WITHIN POOL OUTLINE OF THE VERKHNEKAMSKY DEPOSIT OF POTASSIUM AND MAGNESIUM SALTS
}

\author{
Vladislav I. Galkin 1 , \\ vgalkin@pstu.ru
}

\section{Oleg A. Melkishev ${ }^{1}$,} melkishev@pstu.ru

\author{
Stanislav V. Varushkin 2,1 , \\ geologist-07@mail.ru \\ 1 Perm National Research Polytechnic University, \\ 29, Komsomolskiy avenue, Perm, 614990, Russia. \\ 2 LLC «LUKOIL-PERM», \\ 62, Lenin street, Perm, 614990, Russia.
}

\begin{abstract}
The relevance of the research. In recent years, there have been significant changes in the territorial distribution of oil and gas reserves and resources in Perm region. At present, all large and medium-sized oil and gas deposits have been explored in the territory of the platform part of Perm region. At the same time within the Solikamsk petroleum district of the Volga-Ural petroleum province the possibility of opening such deposits actually exists, especially in pool outline of the Verkhnekamsky field of potassium and magnesium salts. Selection of objects and determination of their order of entry into prospecting and appraisal drilling play an important role for successful geological exploration works.

The main aim of the article is to identify the priority objects for setting up prospecting and appraisal drilling based on statistical models of oil and gas forecasts.

Object: lead and prepared oil and gas structures of the Solikamsk petroleum district of the Volga-Ural petroleum province located in pool outline of the Verkhnekamsky field of potassium and magnesium salts.

Methods: development of multidimensional models by the method of recursive regression analysis.

Results. For a comprehensive ranking of all available structures located on the territory of the Verkhnekamsky field of potassium and magnesium salts, a complex zonal-local criterion of oil and gas content - RnкомP - was calculated. The impact of morphological (PukVmorf), migration (Pkm), geochemical (Pukvgh) parameters and gas events data criterion (PnмNX) on the integrated PnкомP indicator was evaluated. From the analysis of the constructed models, it follows that the criteria of Pukvmor,, Pukvgh are more universal, while Pkm, PnMnx are manifested only for the choice, which includes the structures with the highest values of the complex indicator Pnkomp. The most perspective objects were selected for input into prospecting and appraisal drilling.
\end{abstract}

\section{Key words:}

The Verkhnekamsky field of potassium and magnesium salts, the Solikamsk petroleum district, the Volga-Ural petroleum province, recursive regression analysis, conditional complex probability, prospecting and appraisal drilling, geological exploration.

\section{REFERENCES}

1. Kudryashov A.I. Verkhnekamskoe mestorozhdenie soley [The Verkhnekamsky field of salts]. Perm, Mining Institute UB RAS, 2013. 429 p.

2. Varushkin S.V., Kozlova I.A. The ability of conduction of prospecting-evaluation surveys at objects located under a layer of potassium and magnesium salts the Verkhnekamsky deposit). Perm Journal of Petroleum and Mining Engineering, 2012, vol. 11, no. 3, pp. 8-15. In Rus.

3. Andreiko S.S., Ivanov O.V., Litvinovskaia N.A. Prognozirovanie predotvrashchenie gazodinamicheskikh iavlenii iz pochvy pri prokhodke podgotovitelnykh vyrabotok $v$ podrabotannom massive solianykh porod [Forecasting and prevention of the gasdynamic phenomena from the soil at a driving of preparatory developments in the earned additionally massif of salt breeds]. Perm, PNRPU Publ. 2015. $158 \mathrm{p}$

4. Andreiko S.S., Ivanov O.V., Nesterov E.A. Fight against the gasdynamic phenomena when developing the Verkhnekamsky and Starobinsky fields of potash salts. Scientific research and innovation, 2010, vol. 3, no. 4, pp. 34-37. In Rus.

5. Andreiko S.S., Ivanov O.V., Kharintsev A.V., Chistiakov A.N Prognozirovanie vybrosoopasnykh zon plastov pri razvedke razrabotke Verkhnekamskogo mestorozhdeniia kaliinykh solei [Forecasting of the combustion zones of layers at exploration an development of the Verkhnekamsky field of potash salts]. Mining Journal, 2008, no. 10, pp. 34-36.

6. Shaikhutdinov A.N. Development of probabilistic models for predicting of oil and gas content for Upper-Jurassic sediments (on the example of the territory of activity of TPP «Kogalymneftegaz»). Perm Journal of Petroleum and Mining Engineering, 2014, no. 11, pp. 11-28. In Rus.

7. Martyushev D.A., Zaytsev R.A. Influence of oil field reef carbonate reservoir petrophysical parameters of tournasianfamennian deposits in Upper Kama on well productivity. Bulletin of the Tomsk Polytechnic University. Geo Assets Engineering, 2019, vol. 330, no. 11, pp. 77-85. In Rus. DOI: 10.18799/24131830/2019/11/2350.

8. Koshkin K.A. Development of probabilistic and statistical models for evaluation of oil and gas potential of T12-b and Bb reservoirs of Pozhvinskiy sector. Perm Journal of Petroleum and Mining Engineering, 2018, vol. 17, no. 1, pp. 4-15. In Rus. DOI: 10.15593/2224-9923/2018.1.1.

9. Rastorguev M.E. Using discriminant analysis for the interpretation of gas logging data on the example of the Pavlov oil field. Perm Journal of Petroleum and Mining Engineering, 2019, vol. 19, no. 1, pp. 39-55. In Rus. DOI: 10.15593/2224-9923/2019.1.4.

10. Fadeev A.P. A procedure for evaluation of the effect of water injection into a reservoir on oil production on example of Tournaisian deposits of the Sosnovskoe gas-oil field. Perm 
Journal of Petroleum and Mining Engineering, 2018, vol. 18, no. 2, pp.157-177. In Rus. DOI: 10.15593/2224-9923/2018.4.6.

11. Davydenko A.Yu. Veroyatnostno-statisticheskie metody $v$ geologo-geofizicheskikh prilozheniiakh [Probabilistic and statistical methods in geologicgeophysical applications]. Irkutsk, IGTU Publ., 2007. 29 p.

12. Devis J.S. Statisticheskii analiz dannykh v geologii [The statistical analysis of data in geology]. Moscow, Nedra Publ., 1990. Book 1, $319 \mathrm{p}$.

13. Mikhalevich I.M. Primenenie matematicheskikh metodov pri analize geologicheskoy informatsii (s ispolzovaniem kompyuternykh tekhnologiy: Statistica) [Application of mathematical methods in the analysis of geological information (with use of computer technologies: Statistica)]. Irkutsk, IGU Publ., 2006. 115 p.

14. Porotov G.S. Matematicheskie metody modelirovaniya $v$ geologii [Mathematical methods of modeling in geology]. St. Petersburg, St. Petersburg State Mining Institute (Technical University) Publ. House, 2006. 223 p.

15. Chini R.F. Staticheskie metody v geologii [Static methods in geology]. Moscow, Mir Publ., 1986. 189 p.

16. Armstrong M. Basic linear geostatistics. Berlin, Springer, 1998 $155 \mathrm{p}$.

17. Bartels C.P.A., Ketellapper R.H. Exploratory and explanatory statistical analysis of spatial data. Boston, Martinus Nijhoff Publ., 1979. $268 \mathrm{p}$.

18. Goodwin N. Bridging the gap between deterministic and probabilistic uncertainty quantification using advanced proxy based methods. SPE Reservoir Simulation Symposium 2015. Houston, Richardson Publ., 2015. pp. 1796-1868.

19. Darling T. Well logging and formation evaluation. Eastbourne, Gardners Books, 2010. $336 \mathrm{p}$.

20. Tran D.T., Gabbouj M., Iosifidis A. Multilinear class-specific discriminant analysis. Pattern Recognition Letters, 2017, vol. 100, pp. 131-136. DOI: 10.1016/j.patrec.2017.10.027.

21. Horne R.N. Modern well test analysis: a computer aided approach Palo Alto, PetrowayInc, 2006. 257 p.

22. Houze O., Viturat D., Fjaere O.S. Dynamic data analysis. Paris, Kappa Engineering, 2008. 694 p.

23. Maurya S.P., Singh N.P., Singh K.H. Geostatistical Inversion Seismic Inversion Methods: A Practical Approach. Cham, Springer International Publ., 2020. 216 p. DOI: 10.1007/978-3030-45662-7.

24. Montgomery D.C., Peck E.A. Introduction to liner regression analysis. New York, John Wiley \& Sons, 1982. $504 \mathrm{p}$.
25. Van Golf-Racht T.D. Fundamentals of fractured reservoir engineering. Amsterdam, Oxford, New York, Elsevier scientific publishing company, $1982.709 \mathrm{p}$

26. Yarus J.M. Stochastic modeling and geostatistics. Tulsa, Oklahoma, AAPG, 1994. $231 \mathrm{p}$.

27. Galkin V.I., Kozlova I.A., Rastegaev A.V., Vantseva I.V., Krivoshchekov S.N., Voevodkin V.L. K metodike otsenki perspektiv neftegazonosnosti Solikamskoi depressii po kharakteristikam lokalnykh struktur [On the methodology for assessing the prospects of oil and gas potential of the Solikamsk depression according to the characteristics of local structures]. Oilfield engineering, 2010, no. 7, pp. 12-17.

28. Galkin V.I., Rastegaev A.V., Galkin S.V. Veroyatnostnostatisticheskaya otsenka neftegazonosnosti lokalnykh struktur [Probabilistic-statistical evaluation of the gas content of local structures]. Ekaterinburg, URo RAN, 2001. 277 p.

29. Voevodkin V.L., Galkin V.I., Kozlova I.A., Krivoshhekov S.N., Kozlov A.S. O masshtabakh migratsii uglevodorodov v predelakh Solikamskoy depressii Preduralskogo progiba i vozmozhnostyakh ee ispolzovaniya dlya prognoza neftegazonosnosti. K metodike otsenki perspektiv neftegazonosnosti Solikamskoy depressii po kharakteristikam lokalnykh struktur [The extent of migration of hydrocarbons within the Ural Solikamskaya depression trough and it could be used for the prediction of oil and gas potential. By the methods of assessment of petroleum potential Solikamskaya depression characteristics of local structures]. Geology, geophysics and development of oil and gas fields, 2010, no. 12, pp. 6-12.

30. Galkin V.I., Krivoshhekov S.N. Razrabotka veroyatnostnostatisticheskikh modeley neftegazonosnosti $\mathrm{v}$ usloviyakh ekologicheski napryazhennoy territorii Verkhnekamskogo mestorozhdeniya kaliyno-magniyevykh soley [Development of probability-statistical models of oil-gas content forecast in the conditions of ecologically intense territory of the Verkhnekamsky deposit of potassium salts]. Environmental protection in oil and gas complex, 2010, no. 11, pp. 52-53.

31. Galkin V.I., Melkishev O.A., Varushkin S.V., Andreiko S.S., Lialina T.A. Development of the statistical model to forecast oil and gas potential according to gas content in the Verkhnekamskoe deposit of potassium and magnesium salts. Perm Journal of Petroleum and Mining Engineering, 2020, vol. 20, no. 1, pp. 4-13. In Rus. DOI: 10.15593/2224-9923/2020.1.1

Received: 13 June 2020.

\section{Information about the authors}

Vladislav I. Galkin, Dr. Sc., professor, head of the Oil and Gas Geology Department, Perm National Research Polytechnic University.

Oleg A. Melkishev, Cand. Sc., associate professor, Perm National Research Polytechnic University.

Stanislav V. Varushkin, lead geologist, LLC «LUKOIL-PERM»; post-graduate student, Perm National Research Polytechnic University. 